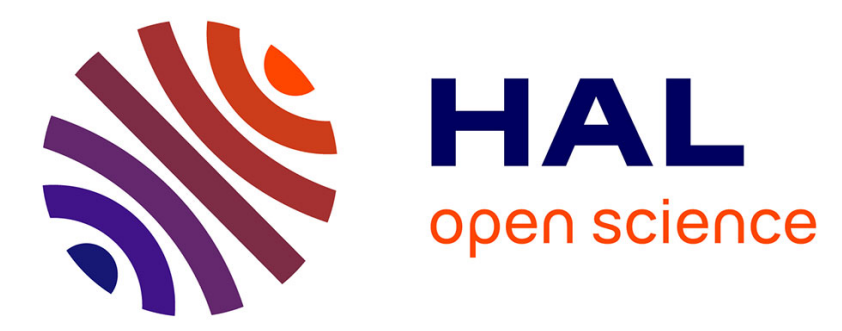

\title{
Effect of Applied Electrical Field and the Initial Soil Concentration on Species Recovery During Application of the Electroremediation Process
}

\author{
V. Pomès, A. Fernández, D. Houi
}

\section{- To cite this version:}

V. Pomès, A. Fernández, D. Houi. Effect of Applied Electrical Field and the Initial Soil Concentration on Species Recovery During Application of the Electroremediation Process. Process Safety and Environmental Protection, 2002, 80 (5), pp.256 - 264. 10.1205/095758202762277614 . hal-01851835

\section{HAL Id: hal-01851835 \\ https://imt-mines-albi.hal.science/hal-01851835}

Submitted on 15 Nov 2019

HAL is a multi-disciplinary open access archive for the deposit and dissemination of scientific research documents, whether they are published or not. The documents may come from teaching and research institutions in France or abroad, or from public or private research centers.
L'archive ouverte pluridisciplinaire HAL, est destinée au dépôt et à la diffusion de documents scientifiques de niveau recherche, publiés ou non, émanant des établissements d'enseignement et de recherche français ou étrangers, des laboratoires publics ou privés. 


\title{
EFFECT OF APPLIED ELECTRICAL FIELD AND THE INITIAL SOIL CONCENTRATION ON SPECIES RECOVERY DURING APPLICATION OF THE ELECTROREMEDIATION PROCESS
}

\author{
V. POMÈS ${ }^{1}$, A. FERNÁNDEZ ${ }^{1}$ and D. HOUI ${ }^{2}$ \\ ${ }^{1}$ Laboratoire de Génie des Procédés des Solides Divisés, Centre Energétique Environnement, Abli, France \\ ${ }^{2}$ Institut de Mécanique des Fluides de Toulouse, Toulouse, France
}

$\mathrm{E}$ lectrokinetic phenomena can be employed for a soil decontamination process generally called electroremediation. The ionic species in solution migrate through a porous medium essentially by electro-osmosis and electromigration. The aim of this work was to contribute to knowledge of this process by studying the effect of some operating conditions on the species recovery through an experimental program. The influence of the electrical field applied to the medium and the initial concentration of the soil solution, in particular, are studied. First, the electrokinetic transport phenomena are presented. Then, the experimental setup and procedures carried out are described. The set-up consists of a specific electroremediation cell containing a Na-doped kaolinite medium. Chemical reactions were limited by using the sodium as a tracer. The experimental results show the important coupling existing between solution concentration and the electrical current and their influence on both the amount and the rate of transported mass. Moreover, the dependence of the electro-osmotic coefficient on the electrical field applied was demonstrated. The influence of the solution concentration on the electro-osmosis is not obvious, probably due to the light modification of the zeta potential for the system studied.

Keywords: electrokinetic transport; electromigration; electro-osmosis; electro-reclamation process; soil remediation.

\section{INTRODUCTION}

Electrokinetic transport phenomena have been known from the beginning of the twentieth century and some applications, like electro-osmotic dewatering ${ }^{1-3}$ and models, have been developed during the last 50 years ${ }^{4}$. The most important applications on soil treatment, which can be called electroremediation, began nearly 15 years ago in research laboratories in the Netherlands ${ }^{5}$, and in the USA ${ }^{6,7}$, almost at the same time. Electrokinetic processes, which can be used in $s^{i t u} u^{8}$, are able to treat ionic pollutants such as heavy metals $^{9}$, or other cationic species like arsenic ${ }^{10}$ and anionic species like fluorine ${ }^{11}$, but also some ionic or soluble hydrocarbons like phenol ${ }^{12,13}$.

Process feasibility and efficiency have been demonstrated at the laboratory scale and some industrial applications have been carried out, even where the phenomena involved and their coupling remain poorly understood. Soils are very complex chemical systems with significant implications for pollutant behaviour, such as retention by ion exchange or other chemical reactions ${ }^{14}$. In addition, they are usually multicomponent systems with different levels of species concentration, as opposed to the monocomponent diluted systems used in experiments, with important consequences for the electrical behaviour of the system and the pollutant recovery, as will be shown later. All of these factors make the transposition of experimental results from the laboratory to the field difficult ${ }^{15}$.

Usually, and independently of any chemical reactions in soils, two transport phenomena are considered to take place when an electrical field is applied to a consolidated porous medium: electro-osmosis, a convective water transport, and electromigration, a forced diffusional species transport. Electrophoresis, the particle transport under an electrical field, is usually neglected in soil applications ${ }^{13}$. Electrochemical reactions at the electrodes guarantee the continuity of the electrical current transportation, but they also contribute to the practical feasibility of the process. Through electrochemical reactions, the electrical potential applied induces a perturbation of the charge balance in the solution around electrodes: positive at the anode and negative at the cathode. Then, electromigration acts to keep electroneutrality, following the Nerst-Planck theory ${ }^{16}$. As a consequence, the concentration involved in the application of the mass-transport equation by the electromigration mechanism is not the total concentration of the solution, but just the concentration 
necessary to maintain electroneutrality. However, electroosmosis concerns the total concentration of the solution.

Many research groups are working on this subject, and some fundamental problems of definition and use of the involved mechanisms have been reported ${ }^{17,18}$. Acar and Alsawabkeh ${ }^{7}$ have shown that the relative importance of different mechanisms can be estimated through dimensionless numbers, as is common in chemical engineering. Thevanayagam and Rishindran ${ }^{18}$ do the same by calculating the transport rates for different mechanisms involved, which is effectively equivalent. However, these calculations need transport parameters, such as electro-osmotic coefficient or ionic mobility, to be known, that are not constant as is often considered, but a function of the solution concentration ${ }^{19}$, which is changing during the process.

In a previous paper, we tried to use dimensionless analysis in order to determine the relevant transport mechanisms for a non-permeable system. As described in detail by Pomès et $a l^{20}$, an expression of the characteristic time of electrokinetic transport phenomena, $\Gamma_{\mathrm{ek}}$ (electromigration coupled to electro-osmosis), was defined and experimentally validated. Even if the experimental error in this determination is quite important for such tedious experiments, the characteristic times calculated are in fact very different to the transport times usually indicated in the literature ${ }^{18,21}$ (when other phenomena retard the transport). Thus, absolute errors can be considered of little importance.

The aim of this work is to contribute to knowledge on the electroremediation process by studying the effect of some operating conditions on species recovery through experimental work. We have studied in particular the influence of the electrical field applied to the medium and the initial concentration of the species in soil, The electrical gradient imposed on the system directly influences the rates of electromigration and electro-osmosis. The initial concentration in the soil mostly governs soil electrical conductivity and the value of the current intensity obtained, which determines the mass flow density of species displaced by electromigration.

For this, the experimental set-up developed and characterized and a non-reactive ion (the sodium) were used in order to avoid chemical reactions. It is clear that the use of sodium as an ion is not significant from an environmental point of view. However, it is a very good support for those interested in transport mechanism research, for different reasons: it is electrochemically stable; characteristic transport parameters (such as ionic mobility) are well known; and it is easy to analyse (atomic absorption) and manipulate. Chemical reactions with the medium were limited by a pre-saturation treatment. The soil was experimentally modelled with a pure product, kaolinite, to guarantee constant physical properties. The experimental set-up and the well-defined protocol used were the same as those presented in Pomès et al. ${ }^{20}$

In this paper, the most important phenomena, which occur during electroremediation, and their associated physicochemical laws will be presented. They concern transport phenomena, electromigration and electro-osmosis, as well as the characteristic time employed to evaluate transport rates. Next, the experimental set-up and measurement methods will be described and followed by the presentation of the experimental results obtained. Finally, these results will be discussed with particular attention to three aspects: current intensity induced; electro-osmotic flow rate; and species recovery.

\section{THEORETICAL BASIS}

Two electrokinetic phenomena, electromigration and electro-osmosis, are usually considered to take place during the electrodepollution process of a soil. Electromigration is diffusional transport promoted by an electrical potential gradient. Each species moves according to its own ionic mobility, which is a function of the electrical charge, the diffusion coefficient and temperature ${ }^{22}$. Electroosmotic transport takes place only in the presence of solid surfaces. Surface charges on the solid induce a particular organization of ions in the liquid phase close to the surface, called the double layer, which has been studied for many years ${ }^{4}$. Most authors consider electro-osmosis to be produced by the movement of ions in the diffuse layer, which drag water by viscous flow. Electro-osmosis does not concern charge transport because of the neutrality of the phase.

Electrokinetic transport is usually considered as highly monodirectional owing to the electrical field lines, and very often it is mathematically treated as a monodimensionnal system. This approach has been used in the following sections. Moreover, the porous medium was always considered as a homogeneous, isotropic and saturated system.

\section{Electromigration}

Transport by electromigration is only possible if a breaking of electroneutrality balance is imposed to the system. During process application, this is the role of the electrochemical reactions which are able to exchange electrons with electrodes. Then electromigration is produced and acts to maintain electroneutrality.

The mass flow density of one species by electromigration is given by:

$$
\begin{aligned}
& J_{\mathrm{A}, \mathrm{em}}=-\frac{z_{\mathrm{A}}}{\left|z_{\mathrm{A}}\right|} u_{\mathrm{A}}^{*} c_{\mathrm{A}} \nabla \Phi \\
& u_{\mathrm{A}}^{*}=\frac{D_{\mathrm{A}}^{*} F\left|z_{\mathrm{A}}\right|}{R T}=\frac{\theta}{\tau} \frac{D_{\mathrm{A}} F\left|z_{\mathrm{A}}\right|}{R T}
\end{aligned}
$$

with $u_{\mathrm{A}}^{*}$ the effective ionic mobility of species A [which can be calculated by equation (2)] and $\nabla \Phi$ the applied electrical field. The product of $u_{\mathrm{A}}^{*} \nabla \Phi$ gives the rate of the transport. On the other hand, current intensity in the system is given by Faraday's law ${ }^{22}$ [equation (3)].

$$
I=F \sum_{\mathrm{i}} z_{\mathrm{i}} J_{\mathrm{i}}=F \sum_{\mathrm{i}} z_{\mathrm{i}}\left(J_{\mathrm{i}, \mathrm{em}}+J_{\mathrm{i}, \mathrm{d}}\right)
$$

In equation (3), $I$ is the current density and $J_{i}$ represents the mass flow density for all the mechanisms responsible for charge transport, electromigration $\left(J_{\mathrm{em}}\right)$ and diffusion $\left(J_{\mathrm{d}}\right)$ : in fact, electromigration produces in the system a concentration gradient which induces the transport by diffusion of the species. Then, the mass flow density of the species $\mathrm{A}$ is according to the Nerst-Plack equation [equation (4)]. Faraday's law means that the total mass of all the species that can be transported by diffusional mechanisms, when expressed as charge, must be equivalent to the total charge in 
the electrical circuit. However, for many systems diffusion can be neglected and only electromigration is considered ${ }^{23}$.

$$
\begin{aligned}
J_{\mathrm{A}} & =J_{\mathrm{A}, \mathrm{d}}+J_{\mathrm{A}, \mathrm{em}}=-D_{\mathrm{A}}^{*} \nabla c_{\mathrm{A}}-\frac{z_{\mathrm{A}}}{\left|z_{\mathrm{A}}\right|} u_{\mathrm{A}}^{*} c_{\mathrm{A}} \nabla \Phi \\
& =-D_{\mathrm{A}}^{*}\left(\nabla c_{\mathrm{A}}+z_{\mathrm{A}} \frac{F}{R T} c_{\mathrm{A}} \nabla \Phi\right)
\end{aligned}
$$

Simultaneous control of $\nabla \Phi$ and $I$ is impossible due to their coupling through the electrical conductivity of the system, $\kappa$ [equation (5)].

$$
I=\kappa \nabla \Phi
$$

If the solid does not contribute to the system conductivity, $\kappa$ can be calculated from the solution composition:

$$
\kappa=F \sum_{\mathrm{i}} z_{\mathrm{i}} u_{\mathrm{i}}^{*} c_{\mathrm{i}}
$$

In general, the ionic mobility is a function of the total solution concentration ${ }^{19}$, so the electrical conductivity of a solution is a non-linear function. However, $u_{i}^{*}$ is usually considered constant, which is a good approximation at very low concentration. Conversely, at high total concentrations, it decreases when concentration increases, so that it is quite difficult to predict conductivity values at these conditions. During the electrokinetic treatment, concentrations of the system are changing and then conductivity changes too.

Working at constant electrical potential ${ }^{6,9,18}$ allows the control of the rate transport, but electrical intensity (and the amount of species that can be recovered) will be mostly regulated by the system resistivity and it will change during the treatment. On the contrary, working at a constant electrical intensity ${ }^{24,25}$ can be useful for controlling the total amount of species recovered [equation (3)].

\section{Electro-osmosis}

From a microscopic point of view, electro-osmosis is equilibrium between the electrical and viscous forces in the double layer. Several theories have been proposed to explain and to predict electro-osmotic behaviour. The Helmholtz-Smoluckowski theory for electro-osmotic rate in a capillary [equation (7)] is one of the most widely used. The electro-osmotic flow for a system can be calculated by extension of this theory to the overall porous medium ${ }^{14}$ [equation (8)].

$$
v_{\mathrm{eo}}=\frac{\varepsilon \zeta}{\mu} \nabla \Phi
$$

In equation (7), $\varepsilon$ is the dielectric constant of the medium, $\mu$ is the solution viscosity and $\zeta$ is the zeta potential or electrical potential in the shear plane around particles ${ }^{4}$.

$$
Q_{\mathrm{eo}}=v_{\mathrm{eo}} \theta S=\frac{\varepsilon \zeta}{\mu} \theta S \nabla \Phi
$$

The macroscopic treatment of electro-osmosis was principally introduced by Casagrande ${ }^{1}$. He found the electro-osmotic flow mostly independent of pore size distribution and proportional to the applied electrical field:

$$
Q_{\text {eo }}=k_{\mathrm{e}} \nabla \Phi
$$

where $k_{\mathrm{e}}$ was called, by analogy with Darcy's law, electroosmotic coefficient, and it was found to be almost constant $\left(k_{\mathrm{e}}=5 \times 10^{-9} \mathrm{~m}^{2} \mathrm{~s}^{-1} \mathrm{~V}^{-1}\right)$ by Casagrande ${ }^{1}$ for different media.

Macroscopic and microscopic theories can only be joined [equation (10)] if the electro-osmotic coefficient is not considered as a constant: modification of species concentration in solution changes the zeta potential ${ }^{26}$ and the electroosmotic flow $^{27}$. So $k_{\mathrm{e}}$ and $Q_{\mathrm{eo}}$ must be functions of the solution composition, and they must also change during an electrokinetic operation.

$$
k_{\mathrm{e}}=\frac{\zeta \varepsilon}{\mu} \theta
$$

Recovery of pollutants by electro-osmosis can be treated as an other convective transport, so the mass flow density for the species $\mathrm{A}$ is:

$$
N_{\mathrm{A}, \mathrm{eo}}=v_{\mathrm{eo}} c_{\mathrm{A}}=k_{\mathrm{e}} c_{\mathrm{A}} \nabla \Phi
$$

\section{Dimensionless Analysis}

A previous study was carried out concerning characteristic times of different transport phenomena during the electrokinetic process. An expression for the characteristic time of electrokinetic transport was proposed [equation (12)] and experimentally validated.

$$
\Gamma_{\mathrm{ek}}=\frac{\ell}{\left(\frac{z_{\mathrm{A}}}{\left|z_{\mathrm{A}}\right|} u_{\mathrm{A}}^{*}+k_{\mathrm{e}}\right) \nabla \Phi}
$$

The conclusion of this previous work was that diffusion can usually be neglected and, in non-permeable media, electromigration and electro-osmosis are the preponderant transport mechanisms ${ }^{23}$.

\section{EXPERIMENTAL WORK}

\section{Experimental Set-up}

The experimental system (Figure 1) employed was designed and validated during a previous work which is presented in detail elsewhere ${ }^{20}$. It consists of a cylindrical cell placed on a continuous current electrical circuit. The cell contains an Na-doped kaolinite as the porous medium, which is enclosed by a system of grids and filters. The porous medium was put into the cell following a rigorous protocol to guarantee the control of physical properties of the system such as porosity, permeability and degree of saturation, validated by X-ray tomography. The cell was placed horizontally in order to avoid any hydraulic gradient and its absence was verified by following the cathode outlet concentration of sodium during an experiment without application of electrical field. Moreover, an external circulation system, with a fast pumping rate, was used for each electrolytic compartment in order to evacuate the gases produced and to guarantee good mixing. Indeed, a hydrodynamic study previously carried out showed that electrolytic compartments can be considered as perfectly mixed. The cross-sectional area of the cell was $4.71 \times 10^{-3} \mathrm{~m}^{2}$.

A constant electrical field was applied to the titaniumiridium electrodes placed in the electrolytic compartments, at each end of the cell. 


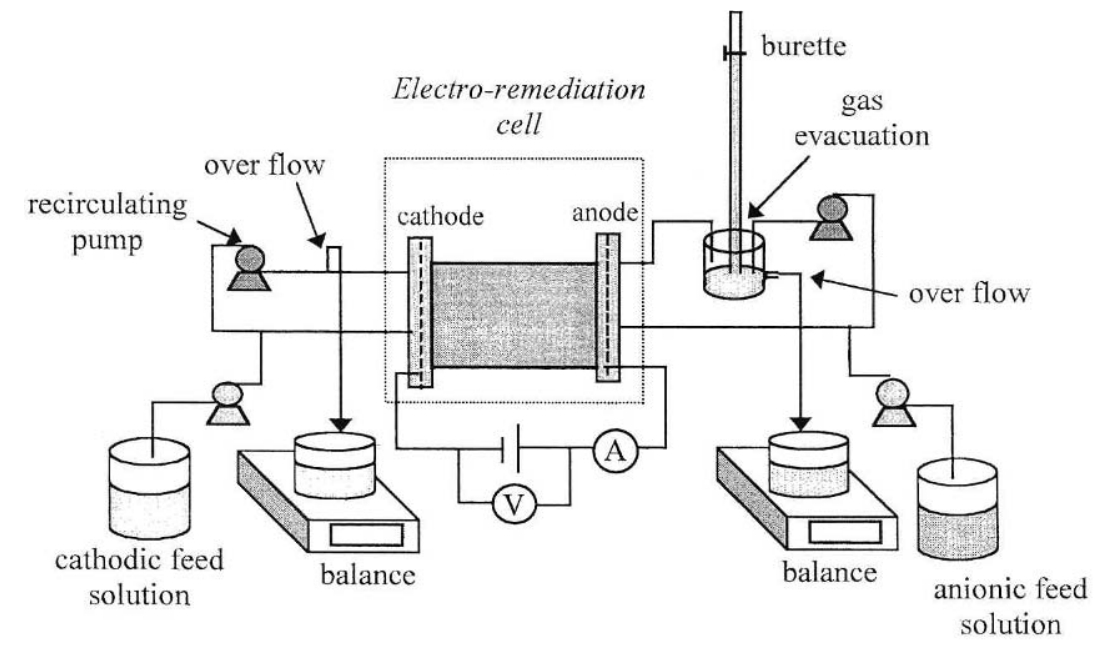

Figure 1. Experimental set-up for electrokinetic studies: electroremediation cell with a gas elimination device at the anode, and fast solution recirculation pumps to guarantee a perfect mixing of the electrolytic compartments. Anionic and cationic feed solutions are introduced to control electrochemical reactions. Overflows are used to measure the electro-osmotic flow rate and to analyse the outlet sodium solution concentration.

\section{Experimental Procedure}

Before each experiment, the kaolinite was saturated with a known concentration of sodium sulphate $\left(\mathrm{Na}_{2} \mathrm{SO}_{4}\right)$ which was considered as the initial sodium concentration in soil, $c_{\mathrm{s}}^{\mathrm{o}}$. It was verified, in previous works at the working conditions, that the sodium can be considered as a tracer for the kaolinite and that sulphate ions did not modify the soil structure. During experiments, the sodium initially present in the medium migrated towards the cathode and the sulphate ions moved towards the anode due to their charge. The initial $\mathrm{pH}$ of the soil was between 5 and 6 .

In order to detect a rise in the sodium concentration at the cathode, a high concentration of sodium in hydroxide form $(\mathrm{NaOH})$ was introduced at the anode, $c_{\text {Anode }}$. The basic $\mathrm{pH}$ of the anode feed solution allowed us to control the electrolysis reaction of water. Then, $\mathrm{H}^{+}$ions were not produced at the anode, maintaining a basic $\mathrm{pH}$ in the compartment. The excess of hydroxide ions stayed in the anode compartment due to their negative charge.

At the cathode, the electrolytic solution introduced was ammonium peroxodisulfate $\left[\left(\mathrm{NH}_{4}\right)_{2} \mathrm{~S}_{2} \mathrm{O}_{8}\right]$ which is easier to reduce than water. It allowed us to avoid water electrolysis and any associated $\mathrm{pH}$ modifications. This solution is naturally acid so its $\mathrm{pH}$ was adjusted to near 5-6 (as the initial soil $\mathrm{pH}$ ) with potassium hydroxide solution. Potassium and ammonium ions remained in the cathode compartment due to their charge, while the $\mathrm{S}_{2} \mathrm{O}_{8}{ }^{2-}$ and $\mathrm{SO}_{4}{ }^{2-}$ ions migrated through the soil towards the anode.

The electrolytic solutions allowed to control the $\mathrm{pH}$ and the electrolytic reactions, to recover the solution samples at the cathode, and to introduce at the anode a sodium solution with a well-known concentration. Finally, by keeping a high and constant conductivity in these compartments, the electrical potential gradient applied between the electrodes was effective in the soil.

During experiment, the current intensity and the electrical potential gradient between the electrodes (which is imposed) were measured by two multimeters. Precision of current intensity measurements was $\pm 5 \times 10^{-3} \mathrm{~A}$, but this parameter is quite sensible to anomalies in the system (for example, the accumulation of a little amount of gas in the electrolytic compartments which introduces a new electrical resistance), in such a way that only its level and behaviour are strictly useful. Sodium concentration at the cathode was measured at the overflow of the electrolytic compartment by atomic absorption at $330.2 \mathrm{~nm}$. Electro-osmosis fluxes were calculated by mass balance at the cathode with $\mathrm{a} \pm 0.01 \mathrm{~g}$ precision balance.

\section{Operating Conditions}

The operating conditions chosen are summarized in Table 1. All the five experiments were conducted with both the same length between the electrodes $(\ell=0.11 \mathrm{~m})$ and anode feed solution $\left(c_{\text {Anode }}=0.1 \mathrm{M}\right)$.

To study the influence of the electrical field on the sodium recovery, three different values were employed, 100, 150 and $200 \mathrm{~V} \mathrm{~m}^{-1}$, while the other operating conditions were kept constant. These experiments are called cell A, cell B and cell C. Using the same procedure, the effect of the initial sodium concentration in the soil was shown using three different solutions to saturate the medium, 0.01, 0.05 and $0.14 \mathrm{M}$, while the other operating conditions were kept constant. These experiments are cell A, cell D and cell E.

Table 1. Operating conditions for electrokinetic experiments.

\begin{tabular}{cccccc}
\hline Experiments & Cell A & Cell B & Cell C & Cell D & Cell E \\
\hline$\nabla \phi\left(\mathrm{V} \mathrm{m}^{-1}\right)$ & 100 & 150 & 200 & 100 & 100 \\
$(\mathrm{~m})$ & 0.11 & 0.11 & 0.11 & 0.11 & 0.11 \\
$c_{\mathrm{s}}^{\mathrm{o}}\left(\mathrm{mol} \mathrm{m}^{-3}\right)$ & 10 & 10 & 10 & 50 & 140 \\
$c_{\text {Anode }}$ & 100 & 100 & 100 & 100 & 100 \\
$\left(\mathrm{~mol} \mathrm{~m}^{-3}\right)$ & & & & & \\
\hline
\end{tabular}




\section{RESULTS AND DISCUSSION}

\section{Current Intensity}

Electromigration and diffusion (which is neglected here) are the two mechanisms able to transport charge owing to the individual transport of ions. Figure 2 shows the evolution of current intensity with time during experiments. Figure 2(a) represents the effect of the electrical potential gradient and Figure 2(b) shows the influence of the initial concentration in the medium.

The current intensity is proportional to the electrical potential gradient through the soil conductivity. Table 2 shows a comparison between experimental and theoretical values of the initial solution conductivity in the system. At low initial concentrations of sodium, soil conductivity can be considered as a linear function of the concentration (ionic mobility being almost constant) and its prediction can be easily carried out. At high initial concentrations (over $50 \mathrm{~mol} \mathrm{~m}^{-3}$ ), the theoretical calculation of this conductivity is more difficult due to the diminution of the ionic mobility. For instance, the values experimentally measured are much lower than the theoretical predictions using the same $u^{*}$ value than for low concentrations.

During the treatment, the current intensity increased rather linearly with time and it is also depending on $\nabla \Phi$.

(a)

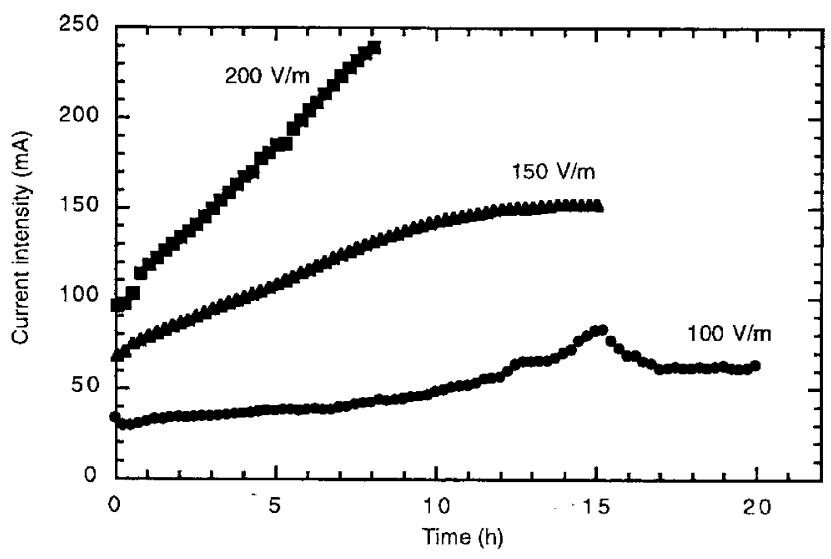

(b)

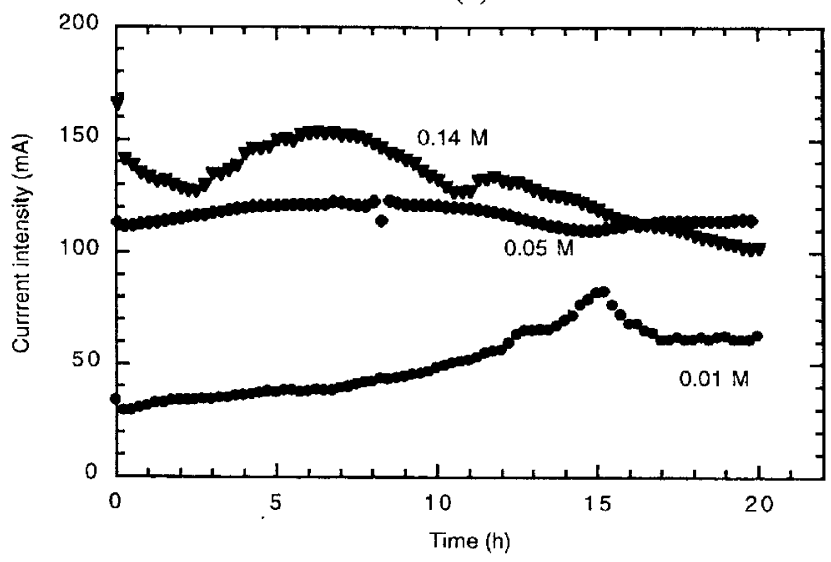

Figure 2. Evolution of the current intensity with time during electrokinetic experiments: (a) influence of the applied electrical field; and (b) influence of the initial sodium concentration in soil.
Table 2. Initial solution conductivity for different experiments: comparison between experimental and theoretical values.

\begin{tabular}{lcc}
\hline & \multicolumn{2}{c}{$\begin{array}{c}\text { Electrical conductivity of the } \\
\text { solution }\left(\mathrm{S} \mathrm{m}^{-1}\right)\end{array}$} \\
\cline { 2 - 3 } Experiment & Experimental & Theoretical $^{\mathrm{a}}$ \\
\hline A & 0.088 & 0.090 \\
B & 0.088 & 0.090 \\
C & 0.090 & 0.090 \\
D & 0.410 & 0.450 \\
E & 1.070 & 1.270 \\
\hline
\end{tabular}

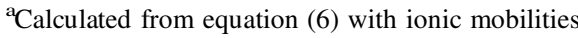
in solution.

That is easy to understand as a result of the increasing sodium concentration in the soil, which is different for each experiment, even if the anode feed solution was always the same. In fact, from Faraday's law, sodium concentration which can pass from the anode to the medium is given by:

$$
\begin{aligned}
I & =F\left(z_{\mathrm{Na}^{+}} J_{\mathrm{Na}^{+}}+z_{\mathrm{SO}_{4}^{2-}} J_{\mathrm{SO}_{4}^{2-}}\right) \\
& =F \nabla \Phi\left(z_{\mathrm{Na}^{+}} u_{\mathrm{Na}^{+}}^{*} c_{\mathrm{Na}^{+}}+z_{\mathrm{SO}_{4}^{2-}} u_{\mathrm{SO}_{4}^{2-}}^{*} c_{\mathrm{SO}_{4}^{2-}}\right)
\end{aligned}
$$

At constant electrical potential gradient and if the ionic mobility of sulphate and sodium can be considered as similar, the electroneutrality condition gives:

$$
I=2 F u^{*} c_{\mathrm{Na}^{+}} \nabla \Phi
$$

For all the experimental conditions we have considered $u^{*}$ to be equal to $2.12 \times 10^{-8} \mathrm{~m}^{2} \mathrm{~s}^{-1} \mathrm{~V}^{-1}$ : ionic mobility of $\mathrm{Na}^{+}$in sulphate solution at infinite dilution is $4.7 \times 10^{-8} \mathrm{~m}^{2} \mathrm{~S}^{-1} \mathrm{~V}^{-1}$, porosity of the system was 0.6 and tortuosity was 1.33 . For each experiment the amount of sodium penetrating into the medium can be calculated from equation (14) as a function of the current density. For instance, at $150 \mathrm{~V} \mathrm{~m}^{-1}$ at the beginning of the experiment the current density over the cross-sectional area of the cell was $14.5 \mathrm{~A} \mathrm{~m}^{-2}$, so the displaced sodium concentration was close to $24 \mathrm{~mol} \mathrm{~m}^{-3}$ (lower than the total concentration in the anode compartment). The higher the electrical potential, the higher the displaced concentration (and the solution conductivity), so the slopes of the curves in Figure 2(a) are also a function of the electrical potential applied.

In experiments with higher initial concentrations in soil, the electrical intensity behaviour is more difficult to understand. The sodium soil concentration changed in each experiment as a function of the current intensity (increased for cell A, decreased for cell $\mathrm{E}$ and stayed constant for cell D) and the current intensity followed it.

\section{Electro-osmosis}

The electro-osmotic flow rate, represented in Figures 3(a) and (b), was measured at the overflow of the cathodic compartment using a balance by difference between feed and outlet flow rates. Figure 3(a) shows the electro-osmotic flow rate measured during experiments $\mathrm{A}, \mathrm{B}$ and $\mathrm{C}$ at different electrical potential gradient. Figure 3(b) represents the influence of the initial soil solution concentration on the electro-osmotic flow rate, through experiments A, D and E. 
(a)

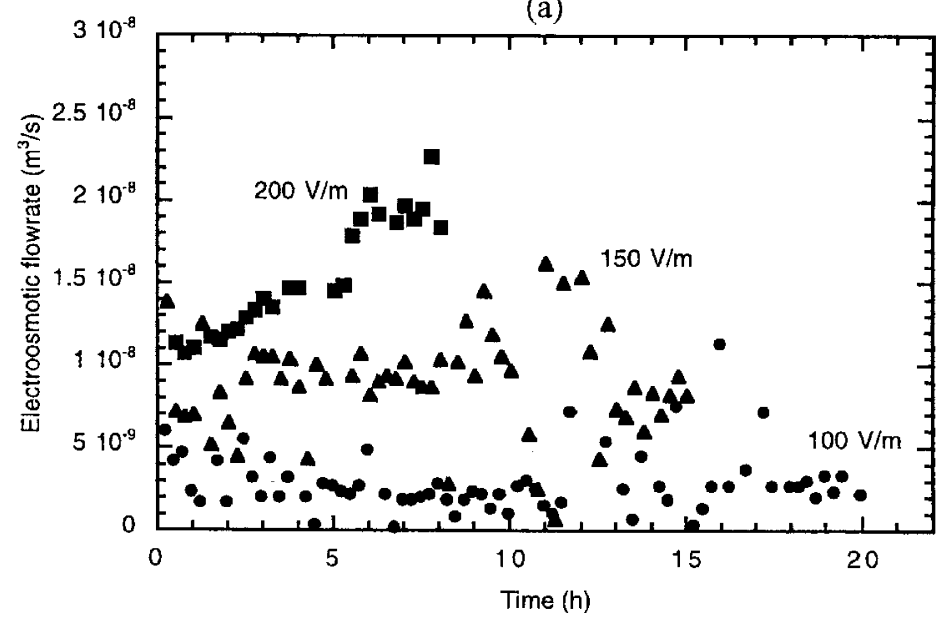

(b)

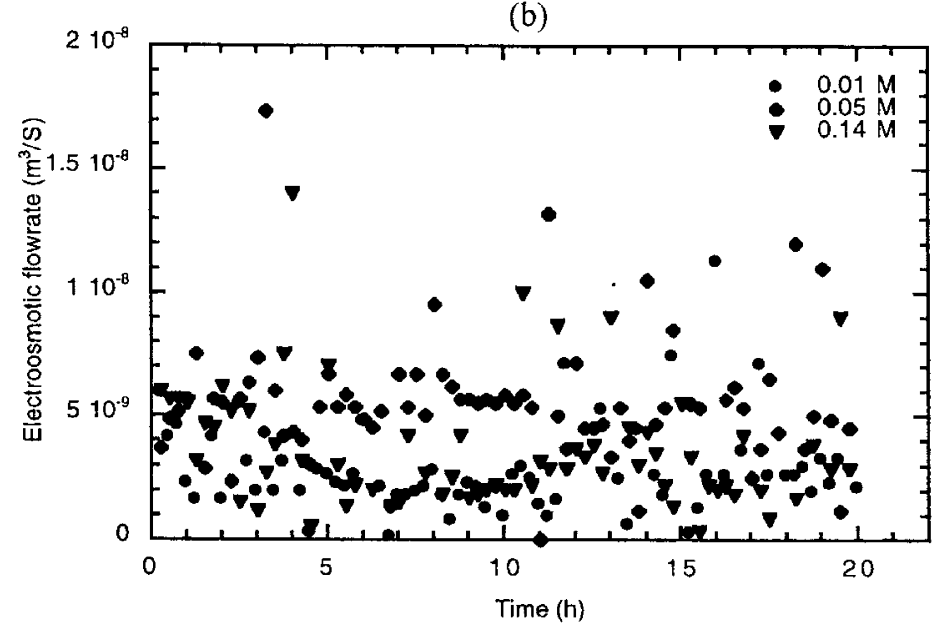

Figure 3. Electro-osmotic flow rate measured during electrokinetic experiments: (a) influence of the applied electrical field; and (b) influence of the initial sodium concentration in soil. The measurement method introduces a high dispersion in results.

The electrical potential gradient applied between the electrodes acts directly on the rate of this transport mechanism [equation (6)], as can be seen in Figure 3(a) where the electro-osmotic flow rate increases with the applied electrical field. In Figure 3(b) a clear effect of the initial concentration of the medium on the value of the electro-osmotic flow rate cannot be observed, as had been theoretically predicted.

As explained before, a relation between the electroosmotic flow rate and the electro-osmotic coefficient can be established (equation 8), where the latter is generally considered as a function of the chemical composition of the system but not dependant on the imposed electrical potential gradient. Figure 4(a) and (b) represents the evolution with time of the electro-osmotic coefficient calculated using equation (8).

At constant electrical potential gradient, the electroosmotic coefficient is expected to be a function of the soil solution concentration, through the zeta potential by equation (10). For the sodium-kaolinite system in similar conditions, the zeta potential is weakly influenced by the total solution concentration ${ }^{26}$ : close to $-17 \mathrm{mV}$ at $10 \mathrm{molm}^{-3}$ and close to $-14 \mathrm{mV}$ for $100 \mathrm{~mol} \mathrm{~m}^{-3}$ at $\mathrm{pH}$ 6. It is possible that our measurement method is not precise enough to evaluate these experimental variations.
Even when the initial sodium concentrations of cells A, B and $\mathrm{C}$ were identical, their changes during experiments were not the same because of the different electrical field applied. However, the behaviour of the electro-osmotic coefficient cannot be attributed to this variation in the medium concentration (except, perhaps, for experiment C) as discussed before. Then we can conclude from experiments $\mathrm{A}$ and $\mathrm{B}$ that the electro-osmotic coefficient is also a function of applied the electrical field.

\section{Sodium Concentration at the Cathode}

Figure 5(a) represents the evolution of the sodium concentration at the cathode with time as a function of the electrical potential gradient. The influence of the initial sodium concentration in soil into sodium recovery is shown in Figure 5(b) for an applied electrical field of $100 \mathrm{~V} \mathrm{~m}^{-1}$.

The effect of $\nabla \Phi$ on current intensity and electro-osmotic flow will be found on the amount of sodium recovery as much as on its rate. Outlet sodium solution concentration depends on electrokinetic transport but also on the cathode volume and outlet flow rate, according to Figure 6 and equation (15) which represents the mass balance for sodium 
(a)

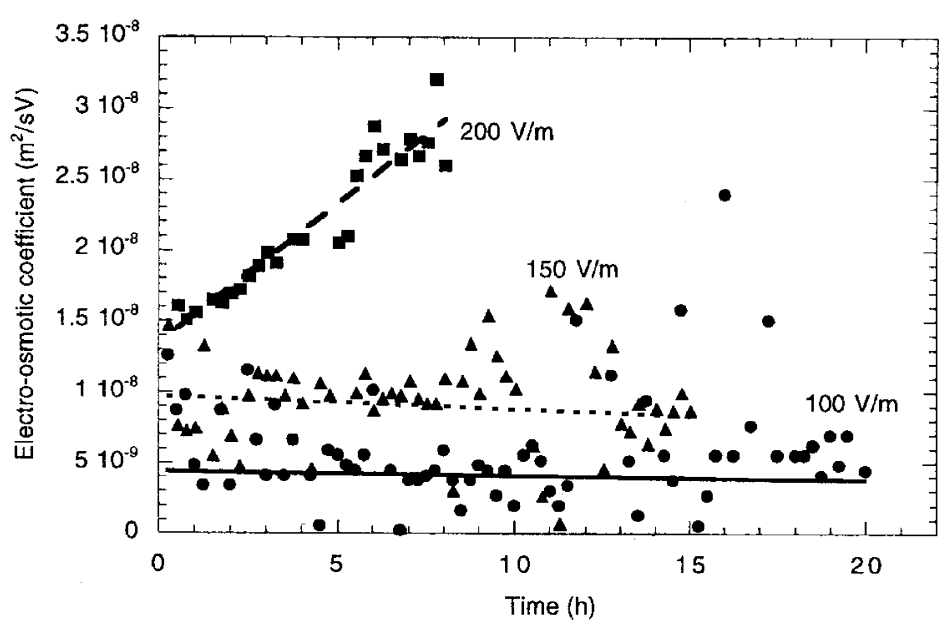

(b)

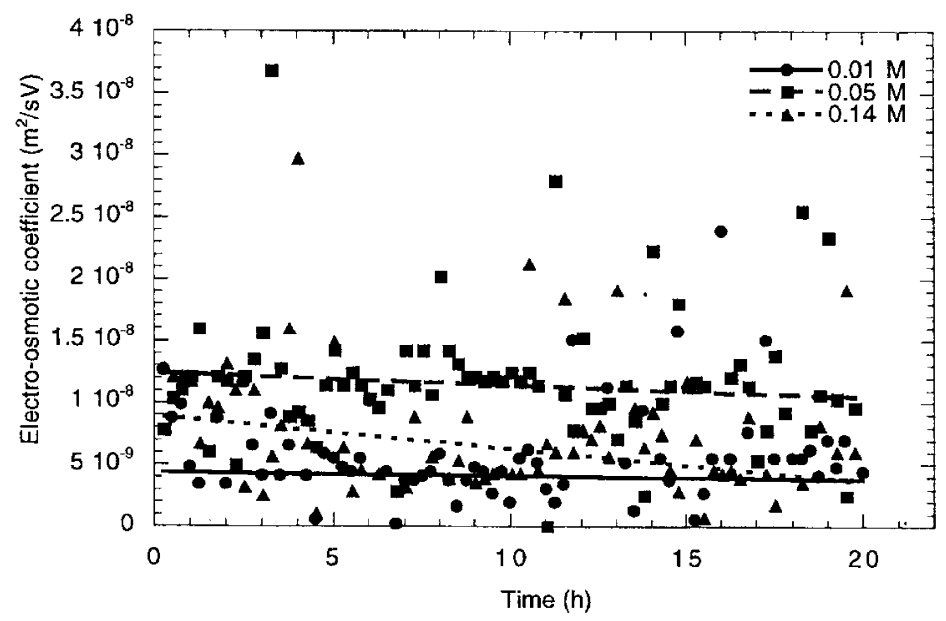

Figure 4. Electro-osmotic coefficient determined from the electrokinetic experiments: (a) influence of the applied electrical field; and (b) influence of the initial sodium concentration. Symbols represent experimental results. Straight lines were obtained by linear regression for each experiment.

species into the cathodic compartment, which is considered perfectly mixed.

$$
Q_{\mathrm{e}} c_{\mathrm{e}, \mathrm{Na}}+Q_{\mathrm{eo}} c_{\mathrm{s}, \mathrm{Na}}+J_{\mathrm{em}, \mathrm{Na}} S-Q_{\mathrm{s}} c_{\mathrm{Na}}(t)=V \frac{\mathrm{d} c_{\mathrm{Na}}(t)}{\mathrm{d} t}
$$

For similar working conditions $\left(Q_{\mathrm{e}}, Q_{\mathrm{s}}, S, V\right)$, the outlet sodium concentration increased with the applied electrical field, in the same way that the current intensity does (see above). At the same time, the time necessary to transport species was reduced. In such a system, previous work ${ }^{23}$ has shown that the preponderant transport mechanisms in the porous medium were electromigration and electro-osmosis, so this time can be considered as the electrokinetic characteristic time $\left(T_{\mathrm{ek}}\right)$. From Figure 5(a) values of characteristic times can be obtained and compared with the theoretical value from equation (12), as Table 3 shows. A practical difficulty for the calculation are the changes of electro-osmotic coefficient for experiments B and C, so an average value over the experiment was used. For all the experiments a value of $u^{*}$ equal to $2.12 \times 10^{-8} \mathrm{~m}^{2} \mathrm{~s}^{-1} \mathrm{~V}^{-1}$ was used. The theoretical results agreed quite well with the experimental ones. Conversely, for experiments D and E, a theoretical calculation of the characteristic times was not carried out because the real values of ionic mobilities are not known at these concentrations.

When initial sodium concentration in soil was increased, sodium concentration at the cathode also increased, but not in the same way. Of course the non-linear relationship between solution concentration and current intensity at high concentrations is found here and the amount of displaced sodium is lower.

\section{CONCLUSIONS}

In order to study electromigration and electro-osmosis phenomena, a well-characterized experimental set-up and protocol was developed ${ }^{20}$. In this work, the effect on the electrokinetic transport of two key variables, the applied electrical field and the initial concentration of species in soil, was analysed. Experimental work was carried out with a tracer in order to avoid chemical reactions. 
(a)

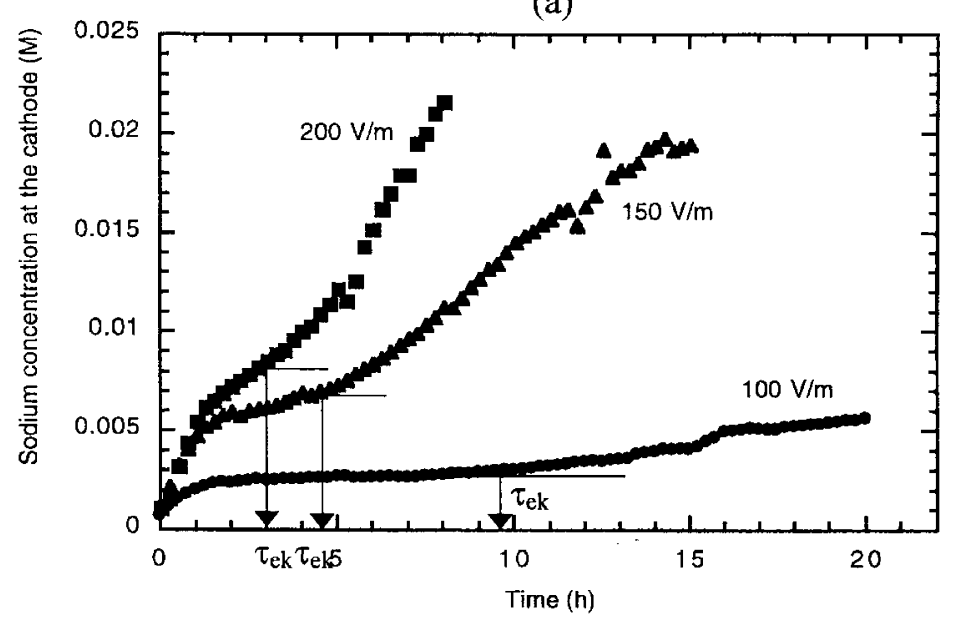

(b)

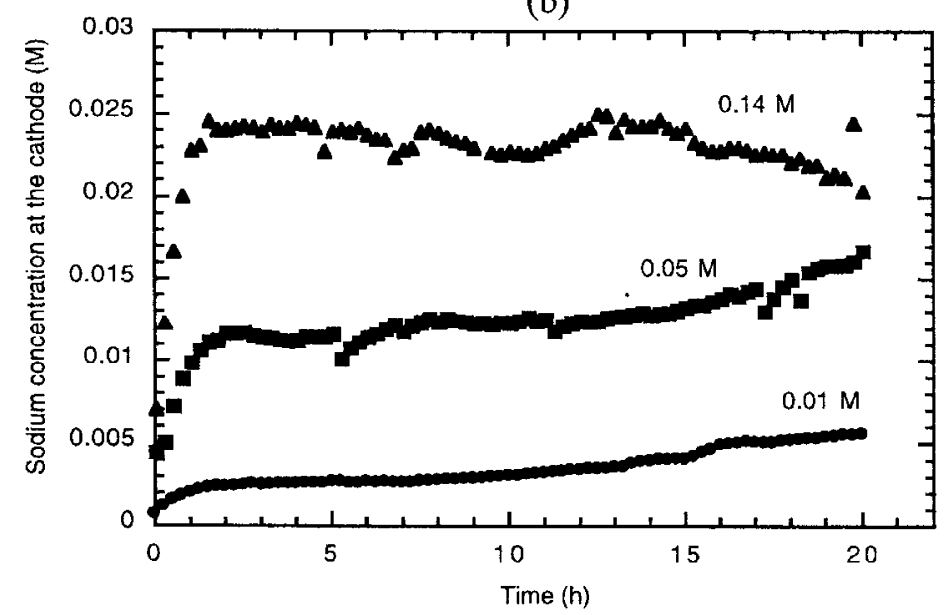

Figure 5. Evolution of the sodium concentration at the cathode with time: (a) influence of the applied electrical field; and (b) influence of the initial sodium concentration in soil. The inlet sodium concentration at the anode was in all the cases $0.1 \mathrm{M}$ as NaOH. In (a) the characteristic times of electrokinetic transport phenomena $\left(\Gamma_{\mathrm{ek}}\right)$ are also represented.

The amount of species recovery and the rate of transport are improved by increasing the applied electrical field. In a first approach this is obvious owing to the linear relationship between the electromigration and electro-osmosis rates with the applied electrical field. Nevertheless, we have also found that the electro-osmotic coefficient changes with electrical field in a stronger way than it does with solution concentration. Solution concentration affects the zeta potential of particles in soil, and the hence electro-osmotic flow rate according to the Helhmoltz-Smoluckowski theory. However, our system was not sensitive enough to detect this influence. During experiments at different constant electrical field, we

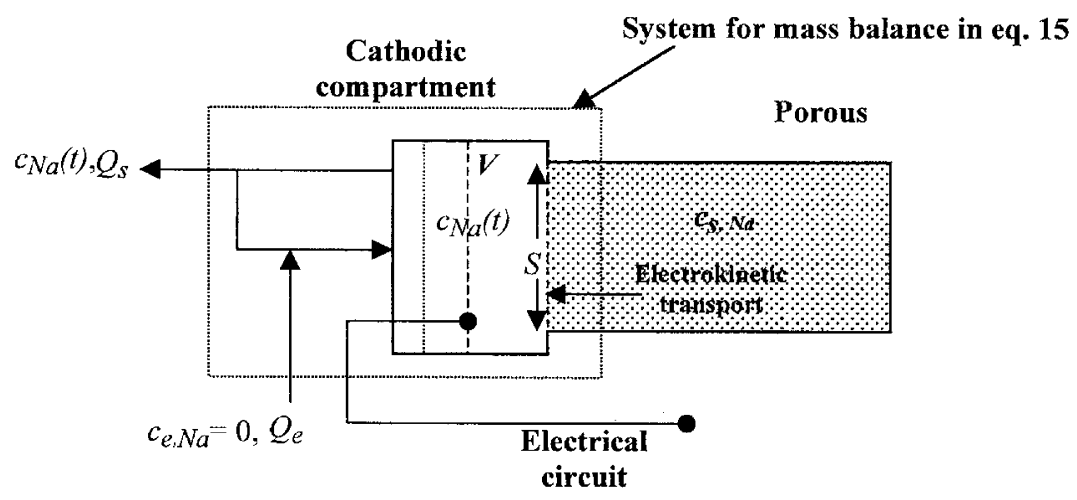

Figure 6. Cathodic compartment system for mass balance. 
Table 3. Experimental and theoretical characteristic times for experiments at different electrical potential gradient.

\begin{tabular}{lccc}
\hline Experiment & $\begin{array}{c}\text { Experimental } \\
k_{\mathrm{e}}\left(\mathrm{m}^{2} \mathrm{~s}^{-1} \mathrm{~V}^{-1}\right)\end{array}$ & $\begin{array}{c}\text { Experimenal } \\
\Gamma_{\mathrm{ek}}(\mathrm{h})\end{array}$ & $\begin{array}{c}\text { Theoretical } \\
\Gamma_{\mathrm{ek}}[\text { from } \\
\text { equation }(12)]\end{array}$ \\
\hline $\mathrm{A}$ & $4.5 \times 10^{-9}$ & 7.5 & 11.9 \\
$\mathrm{~B}$ & $9.0 \times 10^{-9} \mathrm{a}$ & 4.5 & 6.7 \\
$\mathrm{C}$ & $2.2 \times 10^{-8} \mathrm{a}$ & 3.0 & 3.5 \\
\hline
\end{tabular}

${ }^{\mathrm{a}}$ Average value during the experiment.

have found electro-osmotic coefficients to be rather constant and different for experiments A and B. In all cases, concentrations are changing during the experiments and, therefore, both the effect of the electrical field and the soil concentration are difficult to dissociate as in experiment $\mathrm{C}$.

The applied electrical potential gradient results in a current intensity as a function of the medium conductivity, and this current intensity establishes the amount of species which can be displaced through Faraday's Law. However, at high solution concentration, a non-linear relationship exists between ionic concentration and current intensity that means that the presence in solution of higher quantities of species (particularly others than the pollutants) does not improve the process. A solution concentration five times higher gives concentrations at the cathode about five times higher (for instance, 0.01 and $0.05 \mathrm{M}$ ), but this cannot be extrapolated for upper concentrations $(0.14 \mathrm{M})$.

\section{NOMENCLATURE}

\begin{tabular}{|c|c|}
\hline$c_{\mathrm{A}}, c_{\mathrm{i}}$ & solution concentration of species $\mathrm{A}, \mathrm{i}, \mathrm{mol} \mathrm{m}^{-3}$ \\
\hline$c_{\text {Anode }}$ & feed sodium solution concentration at the anode, mol m$^{-3}$ \\
\hline$c_{\mathrm{e}, \mathrm{Na}}$ & $\begin{array}{l}\text { feed sodium solution concentration at the cathode } \\
\text { (usually equal to } 0), \mathrm{mol} \mathrm{m}^{-3}\end{array}$ \\
\hline$c_{\mathrm{Na}}$ & sodium concentration at the cathode, $\mathrm{molm}^{-3}$ \\
\hline$c_{\mathrm{s}}^{\mathrm{o}}$ & initial sodium concentration in soil, $\mathrm{mol} \mathrm{m}^{-3}$ \\
\hline$D_{\mathrm{A}}$ & diffusion coefficient in solution of the species $\mathrm{A}, \mathrm{m}^{2} \mathrm{~s}^{-1}$ \\
\hline$D_{\mathrm{A}}^{*}$ & effective diffusion coefficient of the species $\mathrm{A}, \mathrm{m}^{2} \mathrm{~s}^{-1}$ \\
\hline$F$ & Faraday's constant, $F=96485 \mathrm{C} \mathrm{mol}^{-}$ \\
\hline$I$ & current density, $\mathrm{A} \mathrm{m}^{-2}$ \\
\hline$J_{\mathrm{A}}, J_{\mathrm{i}}$ & $\begin{array}{l}\text { mass flow density by diffusional mechanisms of the } \\
\text { species } \mathrm{A}, \mathrm{i}, \mathrm{molm}^{-2} \mathrm{~s}-1\end{array}$ \\
\hline$J_{\mathrm{i}, \mathrm{d}}$ & $\begin{array}{l}\text { mass flow density by diffusion of the species } i \text {, } \\
\text { mol m } \mathrm{m}^{-2} \mathrm{~s}^{-1}\end{array}$ \\
\hline$J_{\mathrm{A}, \mathrm{em}}, J_{\mathrm{i}, \mathrm{em}}$ & $\begin{array}{l}\text { mass flow density by electromigration of the species: A, i, } \\
\text { mol m}^{-2} \mathrm{~s}^{-1}\end{array}$ \\
\hline$k_{\mathrm{e}}$ & $\begin{array}{l}\text { electro-osmotic coefficient, } \mathrm{m}^{2} \mathrm{~V}^{-1} \mathrm{~s}^{-1} \\
\text { distance between electrodes, } \mathrm{m}\end{array}$ \\
\hline$N_{\mathrm{A}, \text { eo }}$ & $\begin{array}{l}\text { mass flow density by electro-osmosis of the species A, } \\
\text { mol m}{ }^{-2} s^{-1}\end{array}$ \\
\hline$Q_{\mathrm{e}}$ & feed flow rate at the cathode, $\mathrm{m}^{3} \mathrm{~s}^{-1}$ \\
\hline$Q_{\text {eo }}$ & electro-osmotic flow rate, $\mathrm{m}^{3} \mathrm{~s}^{-1}$ \\
\hline$Q_{\mathrm{s}}$ & outlet flow rate at the cathode, $\mathrm{m}^{3} \mathrm{~s}^{-1}$ \\
\hline$R$ & universal gas constant, $R=8.3144 \mathrm{~J} \mathrm{~K}^{-1} \mathrm{~mol}^{-1}$ \\
\hline$S$ & cross-sectional area of the cell, $\mathrm{m}^{2}$ \\
\hline$T$ & absolute temperature, $\mathrm{K}$ \\
\hline$t$ & time, $\mathrm{s}$ \\
\hline $\begin{array}{l}u_{\mathrm{A}}^{*}, u_{\mathrm{i}}^{*} \\
V\end{array}$ & $\begin{array}{l}\text { effective mobility of the species } \mathrm{A}, \mathrm{i}, \mathrm{m}^{2} \mathrm{~V}^{-1} \mathrm{~s}^{-1} \\
\text { volume of the cathode, } \mathrm{m}^{3}\end{array}$ \\
\hline$v_{\mathrm{eo}}$ & rate of the electro-osmotic transport, $\mathrm{ms}^{-1}$ \\
\hline$z_{\mathrm{A}}, z_{\mathrm{i}}$ & charge of the species A, i \\
\hline
\end{tabular}

porosity of the porous medium electrical conductivity of the solution, $\mathrm{S} \mathrm{m}^{-1}$ fluid viscosity, $\mathrm{Pa} \mathrm{s}^{-1}$

tortuosity of the porous medium electrokinetic characteristic time, $s$ zêta potential of the particles of the porous medium, V

\section{REFERENCES}

1. Casagrande, L., 1949, Géotechnique, 1: 3, 159-177.

2. Banerjee, S. and Law, S. E., 1997, Proceedings of the 25th Annual Conference of the Electrostatistics Society of America, Athens, GA, $150-151$.

3. Buijs, P. J., Van Diemen, A. J. G. and Stein, H. N., 1994, Colloids Surf, 85: 29-34

4. Hunter, R. J., 1981, Zêta potential, in Colloid Science: Principles and Applications (Academic Press, London, UK).

5. Lageman, R., 1993, Environ Sci Technol, 27(13): 2648-2650.

6. Shapiro, A. P. and Probstein, P. R. F., 1993, Environ Sci Technol, 27(2): 283-291.

7. Acar, Y. B. and Alshawabkeh, A. N., 1993, Environ Sci Tehcnol, 27(13): 2638-2646.

8. Lageman, R., Pool, W. and Seffinga, G., 1989, Chem Ind, September: 585-590.

9. Pamukcu, S., Newhart, G. and Wittle, J. K., 1995, in Waste Disposal by landfill-GREEN'93 Sarsby (ed). (Balkema, Rotterdam, The Netherlands).

10. Le Hecho, I., Tellier, S. and Astruc, M., 1998, Environ Technol, 19: 1095-1102.

11. Costarramone, N., Tellier, S., Astruc, M., Grano, B. and Lecomte, D., 1998, Waste Mgmt Res, 16(6): 555-563.

12. Acar, Y. B., Li, H. and Gale, R. J., 1992, J Geotech Engng, 118(11): 1837-1852.

13. Probstein, R. F. and Hicks, R. E., 1993, Science, 260: 498-503.

14. Mitchell, J. K., 1993, Fundamentals of Soil Behaviour, 2nd edition (John Wiley, New York, USA).

15. EPA, 1997, Resource Guide for Electrokinetics Laboratory and Field Processes Applicable to Radioactive and Hazardous Mixed Wastes in Soil and Groundwater from 1992 to 1997, Rapport 402-R-97-006 (US Environmental Protection Agency, Center for Remediation Technology and Tools, Washington DC, USA).

16. Helfferich, F., 1962, Ion Exchange (McGraw-Hill, New York, USA).

17. Segall, B. A. and Bruell, C. J., 1992, J Environ Engng, 118(1): 84-100.

18. Thevanayagam, S. and Rishindran, T., 1998, J Geotech Geoenviron Engng, 124(4): 330-338.

19. Levine, I., 1978, Physical Chemistry (McGraw-Hill, New York, USA).

20. Pomès, V., Fernández, A. and Houi, D., 2002, Chem Engng J, 87: 251 260.

21. Dzenitis, J. M., 1997, Environ Sci Technol, 31: 1191-1197.

22. Newman, J. S., 1991, Electrochemical Systems, 2nd edition (PrenticeHall, Englewood Cliffs, NJ, USA).

23. Pomès, V., 2000, Etude du transport électrocinétique d'une espéce non réactive dans un milieu poreux modèle, Thèse de doctorat (INPT, France).

24. Acar, Y. B., Hamed, J. T., Alshawabkeh, A. N. and Gale, R. J., 1994, Geotechnique, 44(2): 239-254.

25. Acar, Y. B. and Alshawabkeh, A. N., 1996, J Geotech Engng, 122(3): 173-184.

26. Vane, L. M. and Zang, G. M., 1997, J Hazard Mater, 55: 1-22.

27. Eykholt, G. R. and Daniel, D. E., 1994, J Geotech Engng, 120(5): 797-815.
Greek symbols $\Phi$ $\nabla \Phi$ applied electrical potential, V applied electrical field, $\mathrm{Vm}^{-1}$ dielectric constant, $\mathrm{Fm}^{-1}$ 